\title{
Nano-Size Biomass Derived from Pomegranate Peel for Enhanced Removal of Cefixime Antibiotic from Aqueous Media: Kinetic, Equilibrium and Thermodynamic Study
}

\author{
Mehdi Esmaeili Bidhendi ${ }^{1}$, Zahra Poursorkh ${ }^{2}$, Hassan Sereshti ${ }^{2}{ }^{*}$, Hamid Rashidi Nodeh ${ }^{3}$ (1) \\ Shahabaldin Rezania ${ }^{4, *(D)}$ and Muhammad Afzal Kamboh ${ }^{5}$ \\ 1 School of Environment, College of Engineering, University of Tehran, Tehran 14155-6135, Iran; \\ esmaeilib@ut.ac.ir \\ 2 Department Chemistry, Faculty of Science, University of Tehran, Tehran 14155-6135, Iran; \\ Sara.poursorkh@gmail.com \\ 3 Food Technology and Agricultural Products Research Centre, Standard Research Institute (SRI), \\ Karaj 31745-139, Iran; rnhamid2@gmail.com \\ 4 Department of Environment and Energy, Sejong University, Seoul 05006, Korea \\ 5 Department of Chemistry, Shaheed Benazir Bhutto University, Shaheed Benazirabad, Sindh 67450, Pakistan; \\ chairman_chemistry@sbbusba.edu.pk \\ * Correspondence: sereshti@ut.ac.ir (H.S.); Shahab.rezania@sejong.ac.kr (S.R.); Tel.: +98-21-6649-5291 (H.S.); \\ +82-10-2902-1046 (S.R.)
}

Received: 17 April 2020; Accepted: 10 June 2020; Published: 13 June 2020

\begin{abstract}
Nano-sized activated carbon was prepared from pomegranate peel (PG-AC) via $\mathrm{NaOH}$ chemical activation and was fully characterized using BET, FT-IR, FE-SEM, EDX, and XRD. The newly synthesized PG-AC was used for cefixime removal from the aqueous phase. The effective parameters on the adsorption process, including solution $\mathrm{pH}(2-11)$, salt effect (0-10\%), adsorbent dosage (5-50 $\mathrm{mg})$, contact time (5-300 $\mathrm{min})$, and temperature $\left(25-55^{\circ} \mathrm{C}\right)$ were examined. The experimental adsorption equilibrium was in close agreement with the type IV isotherm model set by the International Union of Pure and Applied Chemistry (IUPAC). The adsorption process was evaluated with isotherm, kinetic, and thermodynamic models and it is were well fitted to the Freundlich isotherm $\left(R^{2}=0.992\right)$ and pseudo-second-order model $\left(R^{2}=0.999\right)$. The Langmuir isotherm provided a maximum adsorption capacity of $181.81 \mathrm{mg} \mathrm{g}^{-1}$ for cefixime uptake onto PG-AC after $60 \mathrm{~min}$ at $\mathrm{pH} 4$. Hence, the isotherm, kinetic and thermodynamic models were indicated for the multilayer sorption followed by the exothermic physical adsorption mechanism.
\end{abstract}

Keywords: pomegranate peel activated carbon; cefixime micro-pollutant; kinetic; equilibrium; thermodynamic

\section{Introduction}

Antibiotics as emerging pollutants are a major significant global concern since their widespread use as prescription drugs and their potently bioactive properties render them a direct threat to public health from uncontrolled exposures via contaminated drinking water [1-3]. Antibiotics are a large group of medicines including penicillin, cephalosporins (cefixime), fluoroquinolones, aminoglycosides, monobactams, carbapenems, and tetracyclines $[4,5]$. These antibiotics are an important part of modern life because of their vital role in the treatment of a wide range of human and animal infections [6,7]. One common antibiotic used widely in the world is cefixime, which is useful for combating a number of serious bacterial infections such as pneumonia and urinary tract diseases [8,9]. Unfortunately, 
despite the clinical benefits of antibiotics, some of them are not completely metabolized by humans or animals during consumption, resulting in wide side effects $[10,11]$. Therefore, discharging antibiotics into the aqueous environments (rivers, groundwater, and lakes) without adequate treatment results in irreparable harm to human health, especially the promotion of antibiotic resistance of pathogenic microorganisms [12,13], among populations who drink it on a regular basis.

Based on the frequent inability of conventional wastewater treatment methods to remove or reduce the number of unwanted antibiotics to the published control standards, several more effective treatment methods based on photocatalytic degradation [14-16], oxidation, biodegradation, electro-degradation, and adsorption have been introduced [17,18]. Adsorption is considered to be the most attractive treatment method owing to its significant benefits such as economic features, reliability, and its ability to prevent the entry of secondary toxic substances by restricting their transfer into the aquatic environment $[19,20]$. Researchers have studied the capabilities of different adsorbents in relation to antibiotic adsorption such as metal-organic framework, carbon-based material, montmorillonite, zeolite, graphene oxide and activated carbon [21-24]. Owing to low-cost, a high density of active sites, significant adsorption capacity, and a high specific surface area, activated carbons (ACs) are proper adsorbent for pollutant removal of particulate antibiotics [22,25]. Despite the applicability of commercial ACs for wastewater treatment and contaminant removal from aqueous environments, commercial ACs are an expensive option [26,27]. Consequently, research in recent years has sought to produce ACs from affordable natural biomass materials from agricultural wastes such as coconut shell, papaya peel, vine wood, macadamia nut shells, coffee endocarp, olive stones, and walnut shells [28-30]. Regeneration of adsorbents is the key parameter: which ACs can be regenerated with low cost thermal and hydrothermal processes after saturated with pollutants [31,32]. Based on literature, pomegranate based biomass is widely used in pollutant remediation owing to cost-effectiveness [33], eco-friendliness [34], remarkable specific surface area [35], biosorption of malachite green [36], and a cationic and anionic nature [37].

$\mathrm{NaOH}$ has been widely used as promising chemical reagent for preparation of AC with high porosity and uniform shape, pore size distribution, and mesopore volumes [38,39]. In this study, pomegranate peel was used as an AC source, activated via $\mathrm{NaOH}$, for the removal of cefixime in aqueous media. The effective parameters of the removal process were optimized to achieve the best possible performance. In addition, the adsorption kinetics of the removal was investigated with pseudo-first-order, pseudo-second-order, and intra-particle diffusion (Weber-Morris model) models to obtain the most suitable model to understand the adsorption mechanism.

\section{Experimental}

\subsection{Reagents and Materials}

All chemicals used were of analytical grade. Sodium hydroxide $(\mathrm{NaOH})$, hydrochloric acid $(\mathrm{HCl}$, $37 \%$ ) and sodium chloride $(\mathrm{NaCl})$ were purchased from Merck Chemicals (Darmstadt, Germany).

\subsection{Instruments}

To evaluate the surface morphology of PG-AC, a MIRA3 TESCAN (Prague, Czech Republic) and a Carl Zeiss Supra 35-VP (Oberkochen, Germany) field emission-scanning electron microscope (FE-SEM) were used. A Bruker Equinox 55 FT-IR spectrometer (Bremen, Germany) was operated in the wavelength range of 450 to $4000 \mathrm{~cm}^{-1}$ for the investigation of functional groups of PG-AC. A Bruker $X$-ray diffractometer (Bremen, Germany) was used for crystallinity studies of PG-AC in the 2 theta range of $10^{\circ}$ to $90^{\circ}$ with CuK radiation $(\lambda=1.5418 \AA)$. Brunauer-Emmett-Teller (BET) specific surface area, pore volume, and pore size of the prepared PG-AC were investigated using a Belsorp-mini II, BEL Japan Inc. (Osaka, Japan) under $\mathrm{N}_{2}$ gas $\left(28.01 \mathrm{~g} \mathrm{~mol}^{-1}\right)$. 


\subsection{Preparation of Nano-Sized Activated Carbon}

Activation of carbon was conducted by following the procedure described previously [40]. The raw pomegranate peel (PG) was washed, dried, and powdered. Then, $50 \mathrm{~g}$ of the powder was placed in the furnace and heated at $400{ }^{\circ} \mathrm{C}$ for $2 \mathrm{~h}$. The carbonized material was mixed with different ratios of $\mathrm{NaOH}(\mathrm{w}: \mathrm{w} \%)$ in $20 \mathrm{~mL}$ of distilled water, stirred for $2 \mathrm{~h}$, and dried at $130{ }^{\circ} \mathrm{C}$ for $4 \mathrm{~h}$. Then, the dried product was heated in the furnace at $810^{\circ} \mathrm{C}$ for $2 \mathrm{~h}$. The activated carbon (PG-AC) was cooled and washed with distilled water. Different ratios of NaOH:PG-AC (1:1, 1:3, 1:5, and 1:7) were labeled as PG-AC1, PG-AC3, PG-AC5, and PG-AC7 for further experiments.

\subsection{Adsorption Process}

The adsorption efficiency of the prepared activated carbon for removal of cefixime was evaluated in batch experiments. The effects of $\mathrm{pH}(2-11)$, contact time (10-300 $\mathrm{min})$, ionic strength $(0-10 \%)$, and adsorption isotherms (10-200 $\left.\mathrm{mg} \mathrm{L}^{-1}\right)$ on the efficiency of the method were studied carefully. The adsorption behavior (isothermal) of the adsorbent was analyzed by adding $50 \mathrm{mg}$ samples of the adsorbent to $20 \mathrm{~mL}$ samples of cefixime solution at different concentrations. After $60 \mathrm{~min}$ (equilibrium conditions), the adsorbent was removed from the sample solution. The residual concentration of cefixime in the aqueous phase was measured using UV-vis spectrophotometry. Cefixime concentration adsorbed per unit mass of adsorbent $\left(q_{e}\right)$ and the removal efficiency $(R \%)$ was calculated by Equations (1) and (2), respectively.

$$
\begin{aligned}
R \% & =\frac{C_{0}-C_{e}}{C_{e}} \times 100 \\
q_{e} & =\frac{C_{0}-C_{e}}{m} \times V
\end{aligned}
$$

where $q_{e}\left(\mathrm{mg} \mathrm{g}^{-1}\right), C_{0}$, and $C_{e}$ are the equilibrium adsorption capacity and the concentration of cefixime in the aqueous phase before and after adsorption, respectively $\left(\mathrm{mg} \mathrm{L}^{-1}\right), V$ is the volume of the aqueous phase $(\mathrm{mL})$ and $m$ is the mass of the used adsorbent $(\mathrm{g})$.

In order to investigate the regeneration of PG-AC, $50 \mathrm{mg}$ of the activated carbon (cefixime $20 \mathrm{mg} \mathrm{L}^{-1}$ ) was placed in a test tube with $3 \mathrm{~mL}$ methanol and the admixture was shaken for $30 \mathrm{~min}$. The concentration of desorbed cefixime was measured with UV-vis spectrophotometry. The activated carbon was washed with distilled water for reuse in further experiments.

\section{Results and Discussion}

\subsection{Characterization}

\subsubsection{BET Analysis}

The specific surface area of the prepared plain carbon and the activated carbon samples (PG-AC1, PG-AC3, PG-AC5, and PG-AC7) with different ratios of NaOH:PG-AC (1:1, 1:3, 1:5 and 1:7) were analyzed using the Brunauer-Emmett-Teller (BET) technique (Figure 1). The results showed that the BET surface area values obtained for the prepared plain carbon $\left(9.69 \mathrm{~m}^{2} \mathrm{~g}^{-1}\right)$ and activated PG-AC1, PG-AC3, PG-AC5, and PG-AC7 samples were 159, 231, 694, and $455 \mathrm{~m}^{2} \mathrm{~g}^{-1}$, respectively. The obtained pore diameter distribution values were $13.41 \mathrm{~nm}, 4.23 \mathrm{~nm}, 3.01 \mathrm{~nm}, 2.33 \mathrm{~nm}$, and $3.37 \mathrm{~nm}$ for the plain carbon, PG-AC1, PG-AC3, PG-AC5, and PG-AC7, respectively. Pore distributions indicated that the prepared materials were mesoporous in nature $(2<$ pore diameter $<50 \mathrm{~nm})$, PG-AC5 had the highest specific surface area, and the mesoporous structure was selected for further adsorption experiments and characterization. 

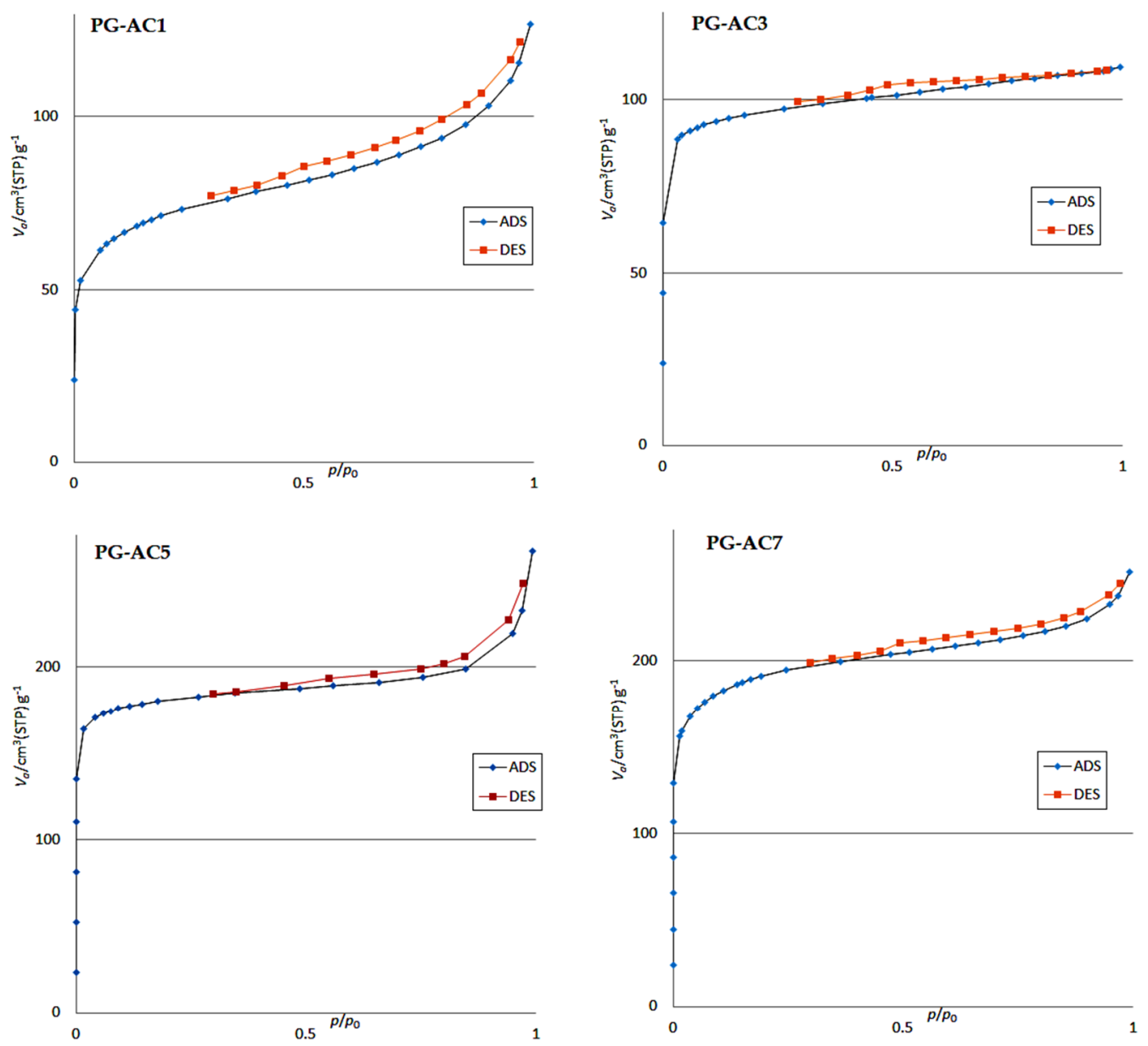

Figure 1. Adsorption-desorption isotherm for BET analysis with different ratios of $\mathrm{NaOH}: \mathrm{PG}-\mathrm{AC}$ (PG-AC1, 1:1), (PG-AC3, 1:3), (PG-AC5, 1:5) and (PG-AC7, 1:7).

\subsubsection{FT-IR Spectroscopy}

Surface functional groups of the prepared activated carbon were studied with IR spectroscopy. Figure 2 shows the FT-IR spectrum of PG-AC5 and the absorption band at $3419 \mathrm{~cm}^{-1}$ is associated with $\mathrm{OH}$ stretching vibration of hydroxyl functional groups, the peaks at 2929 and $2855 \mathrm{~cm}^{-1}$ are related to $\mathrm{C}-\mathrm{H}$ stretching vibrations, and the strong band at $1593 \mathrm{~cm}^{-1}$ corresponds to stretching of the aromatic rings (aromatic $\mathrm{C}-\mathrm{C}$ and $\mathrm{C}=\mathrm{C}$ vibrations). Also, the double band at 1411 and $1316 \mathrm{~cm}^{-1}$ can be attributed to oxygen-containing functional groups, possibly $\mathrm{O}-\mathrm{H}$ of alcohols [41] or in-plane vibration of the O-H bond in carboxylic groups [42]. The band at $1075 \mathrm{~cm}^{-1}$ corresponds to C-O stretching of primary alcohol groups. These results of FT-IR and EDX proved the expected activated carbon was prepared successfully. 


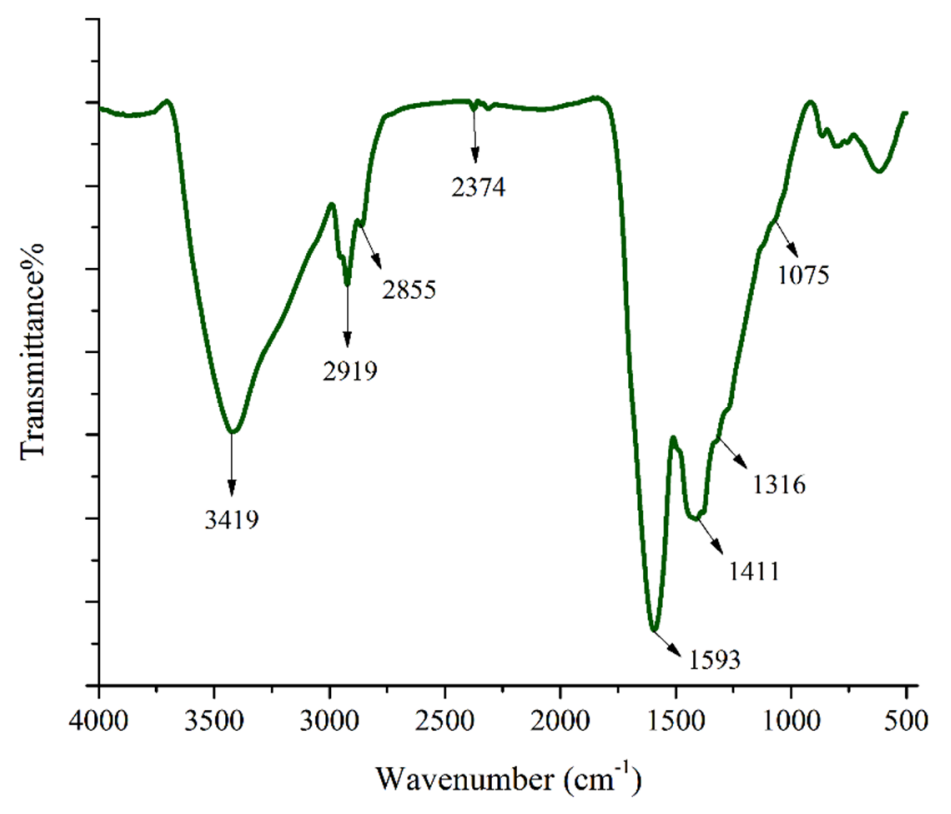

Figure 2. The FT-IR spectrum of PG-AC5 nanomaterial.

\subsubsection{X-ray Diffractometry}

The crystalline structure of PG-AC5 was investigated using the XRD technique. As shown in Figure 3, there was no specific pattern in the spectrum, therefore the prepared powder has an amorphous structure.

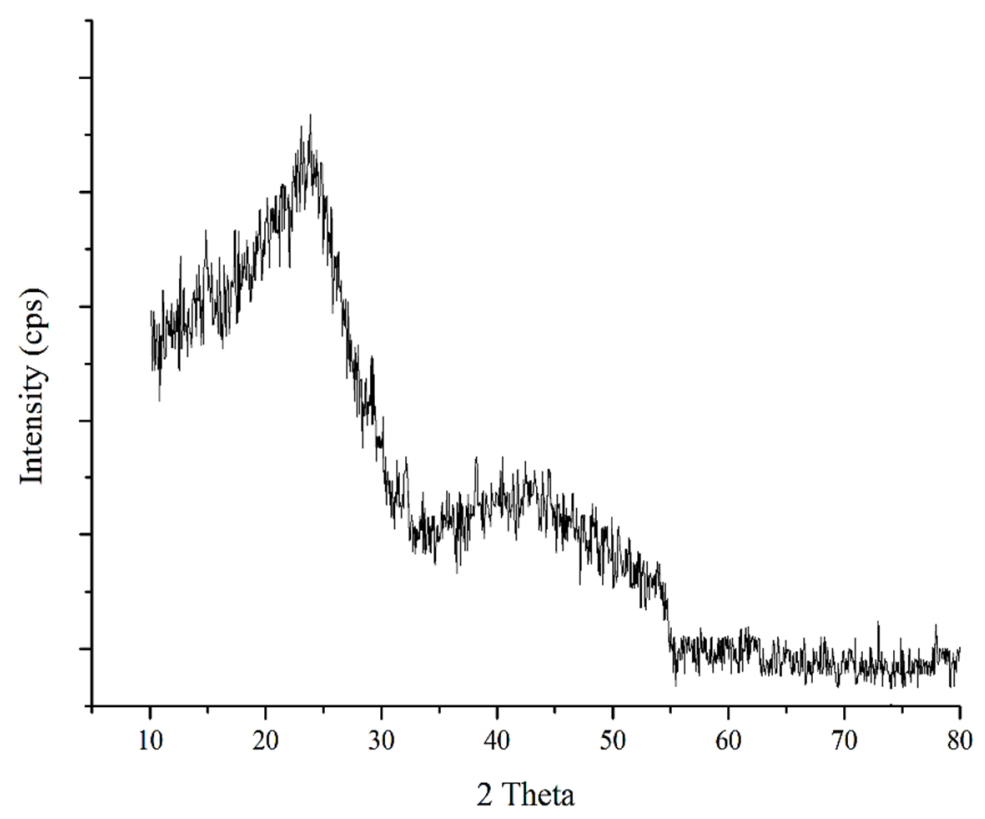

Figure 3. The XRD pattern of pomegranate peel activated carbon.

\subsubsection{Field Emission Scanning Electron Microscopy}

The surface morphological characteristics of PG-AC were studied by FE-SEM. Figure 4A,B show an irregular external surface full of cavities for the activated carbon. In addition, the particles are almost spherical with an average diameter of around $150 \mathrm{~nm}$. Furthermore, the images indicate a porous structure with a high surface area, thus providing a high adsorption capacity. Figure 4C,D show with higher magnification that the surface of the newly synthesized material is uniform and 
there were no aggregations or beads on its surface. The results of the EDX analysis are also shown in Figure 4D. The EDX results indicated that the two major elements forming on PG-AC were carbon (73.24\%) and oxygen (26.76\%), and that the proposed biomass was prepared successfully.

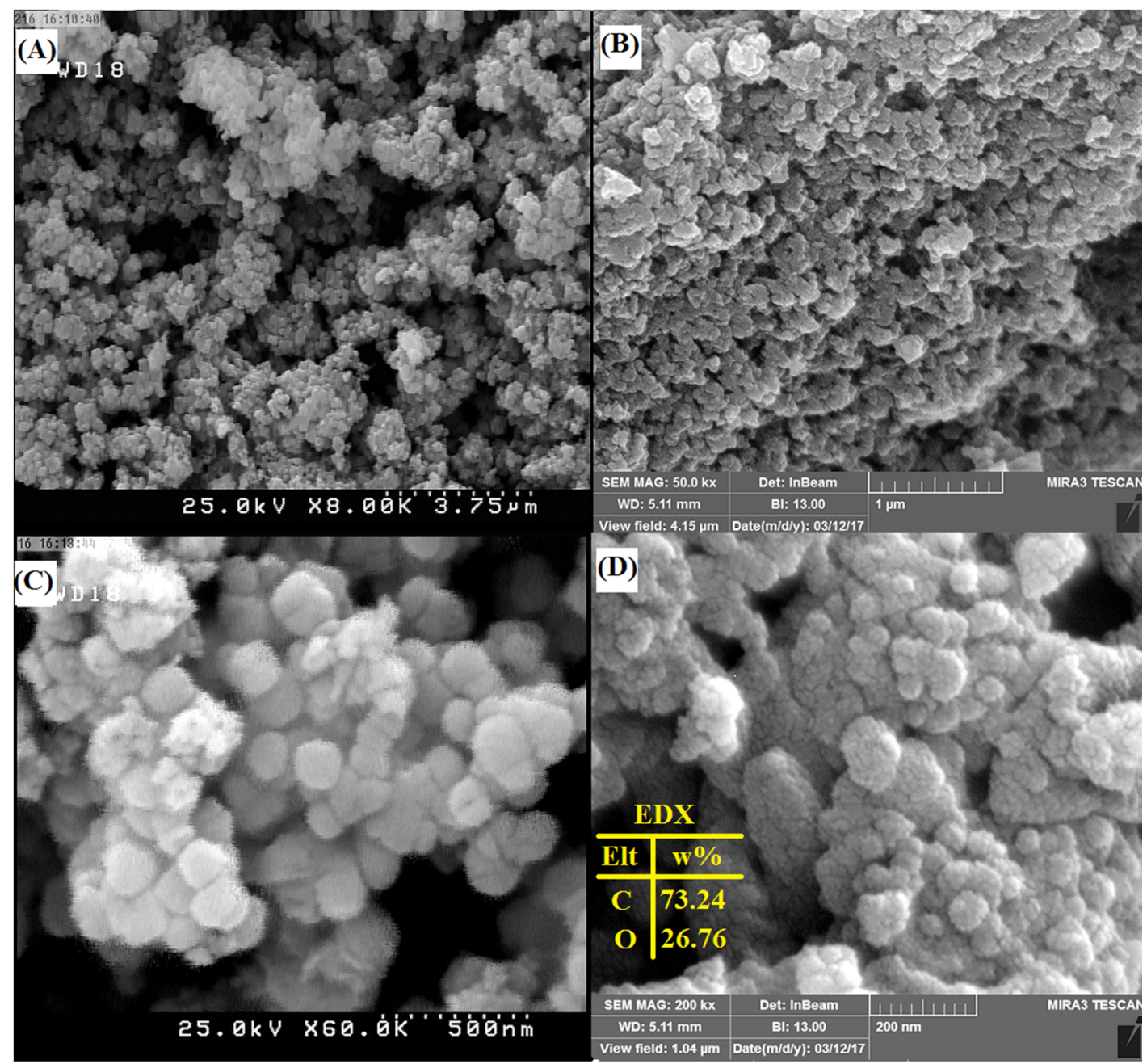

Figure 4. The FE-SEM micrographs of PG-AC5 with different scales (A) $3.75 \mu \mathrm{m},(\mathbf{B}) 1 \mu \mathrm{m}$, (C) $500 \mathrm{~nm}$ and (D) $200 \mathrm{~nm}$.

\subsection{Effect of $p H$}

The $\mathrm{pH}$ of the sample solution may affect the solubility of cefixime, its chemical structure, the sorbent surface charge, and thus the adsorption efficiency [43]. Therefore, the effect of $\mathrm{pH}$ in the range of $2-11$ on the percentage of cefixime removal was studied. Figure $5 \mathrm{~A}$ shows that high removal efficiency for cefixime is at $\mathrm{pH} 2-6$, then declines. Removal efficiency was decreased dramatically by increasing the $\mathrm{pH}$ to more than 6. In addition, with regard to $\mathrm{pK}_{\mathrm{a}}$ of cefixime $\left(\mathrm{pK}_{\mathrm{a}} 2.5\right)$ [44] and Le Chatelier's principle, cefixime itself is a weak acid and may be found in the neutral form in acidic pHs. All these factors proved that the maximum adsorption of cefixime occurs in acidic conditions because of hydrogen bonding and possible electrostatic interactions between activated carbon and this antibiotic. Therefore, $\mathrm{pH} 4$ was selected for further experiments. 

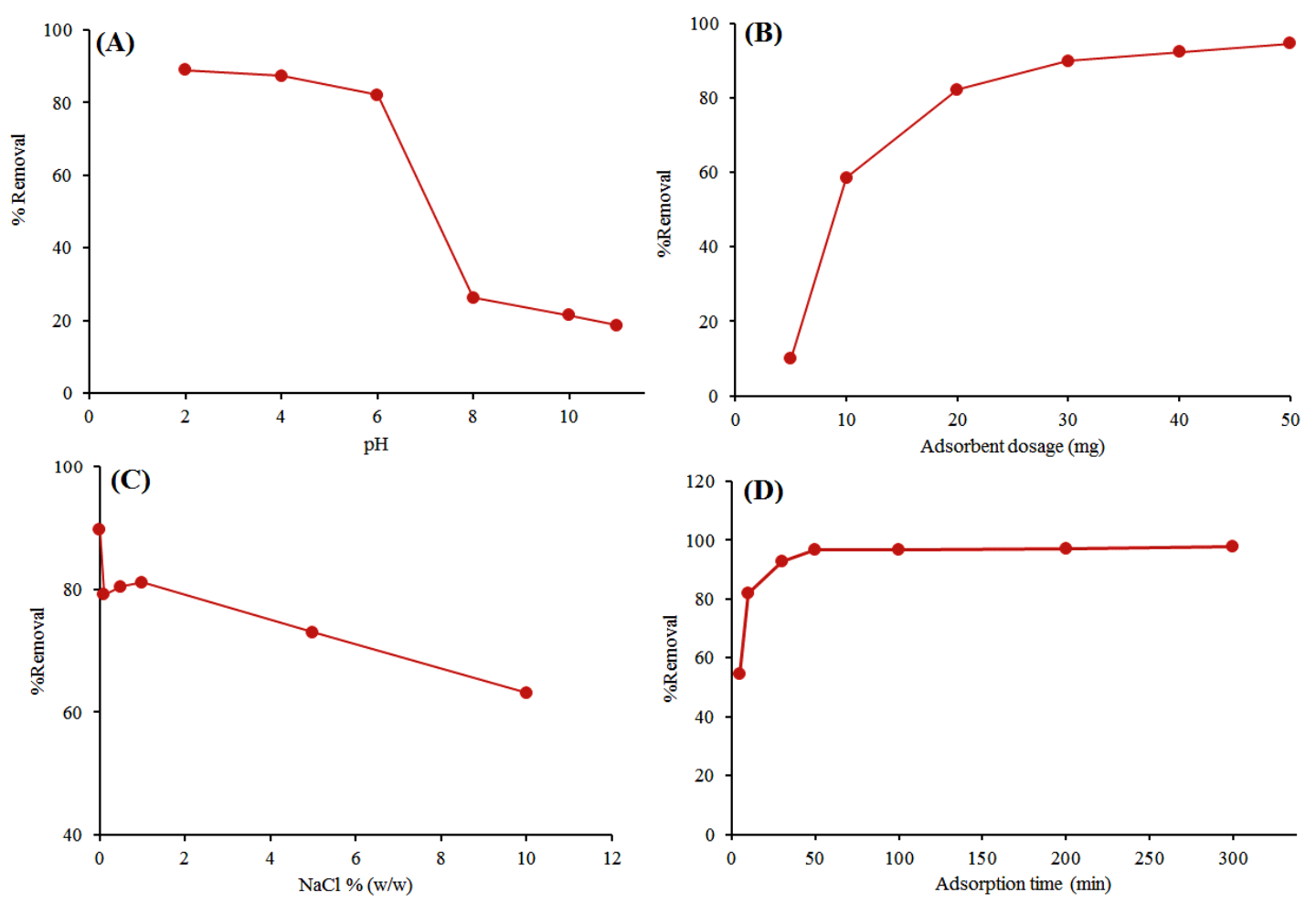

Figure 5. Effect of (A) solution $\mathrm{pH},(\mathbf{B})$ adsorbent dosage, (C) $\mathrm{NaCl}$ percentage and (D) contact time on cefixime removal efficiency.

\subsection{Effect of Adsorbent Dosage}

The adsorbent dosage can directly affect the efficiency of the method and the adsorption capacity [43]. The influence of the adsorbent dose on removal efficiency was explored by testing various adsorbent dosages in the range of 5-50 mg. The experiments were performed using standard cefixime solution of $50 \mathrm{mg} \mathrm{L}^{-1}$ at room temperature, a contact time of $1 \mathrm{~h}$, and $\mathrm{pH} 3$. Figure $5 \mathrm{~B}$ shows that by increasing the adsorbent dosage from 5 to $50 \mathrm{mg}$ the removal percentage enhanced from 49 to $95 \%$. By occupying the available active sites of the adsorbent, the removal efficiency remained virtually constant for adsorbent dosages greater than $50 \mathrm{mg}$.

\subsection{Effect of Salt Concentration}

The influence of the ionic strength on the removal efficiency was studied from 0 to $10 \%$ at the optimized conditions (adsorption time of $1 \mathrm{~h}, \mathrm{pH}$ of 3,50 mg adsorbent and cefixime concentration of $50 \mathrm{mg} \mathrm{L}^{-1}$ ). The results in Figure $5 \mathrm{C}$ show that adding up to $1 \% \mathrm{NaCl}$ had no significant influence on the adsorption of cefixime on AC. It was observed that adsorption decreased to $62 \%$ by the further addition of $\mathrm{NaCl}$ up to $10 \%$. The latter effect probably decreases the strong electrostatic interactions between cefixime and $\mathrm{AC}$, and this is probably due to competition of $\mathrm{Cl}$ anions or $\mathrm{Na}$ cations with the functional groups of cefixime to occupy the active sites. Therefore, for further experiments the effect of salt $(\mathrm{NaCl})$ was ignored.

\subsection{Adsorption Time}

The contact time between the adsorbent and the sample solution is a key factor for the enhanced removal of the target analyte. The influence of this factor on the removal of cefixime was studied in the range of 10-300 min. The concentration of cefixime, $\mathrm{pH}$, and adsorbent dosages was adjusted to $50 \mathrm{mg} \mathrm{L}^{-1}, 3$ and $50 \mathrm{mg}$, respectively. Figure $5 \mathrm{D}$ shows that during the first $50 \mathrm{~min}$, the percentage of cefixime removal increased rapidly and then the system reached equilibrium. This is probably due to the presence of large available active sites at the beginning of the adsorption process. 


\subsection{Adsorption Kinetics}

The experimental data for contact time (Figure 5D) was evaluated with kinetic models, which is useful to describe the adsorption mechanism and mass transfer rate on the surface or interior sites. The adsorption kinetics of cefixime onto the activated carbon was investigated with three well known models of pseudo-first-order, pseudo-second-order and intra-particle diffusion (Weber-Morris model) models. The linear form of the proposed models is described by Equations (3)-(5).

$$
\begin{gathered}
\ln \left(q_{e}-q_{t}\right)=\ln q_{e}-k_{1} t \\
\frac{t}{q_{t}}=\frac{1}{k_{1} q_{e}^{2}}+\frac{t}{q_{e}} \\
q_{t}=k_{i d} t^{1 / 2}+C_{i}
\end{gathered}
$$

where $q_{e}\left(\mathrm{mg} \mathrm{g}^{-1}\right)$ is the equilibrium adsorption capacity, $q_{t}\left(\mathrm{mg} \mathrm{g}^{-1}\right)$ is the adsorption capacity at different times, and $C_{i}$ is the thickness of the boundary layer of intra-particle diffusion. The $k_{1}\left(\mathrm{~min}^{-1}\right)$, $k_{2}\left(\mathrm{~g} \mathrm{mg}^{-1} \mathrm{~min}^{-1}\right)$, and $k_{i d}$ are model constants. The values of kinetic parameters can be obtained from the slope and intercept of the linearized form of proposed models as shown in Figure 6A-C.
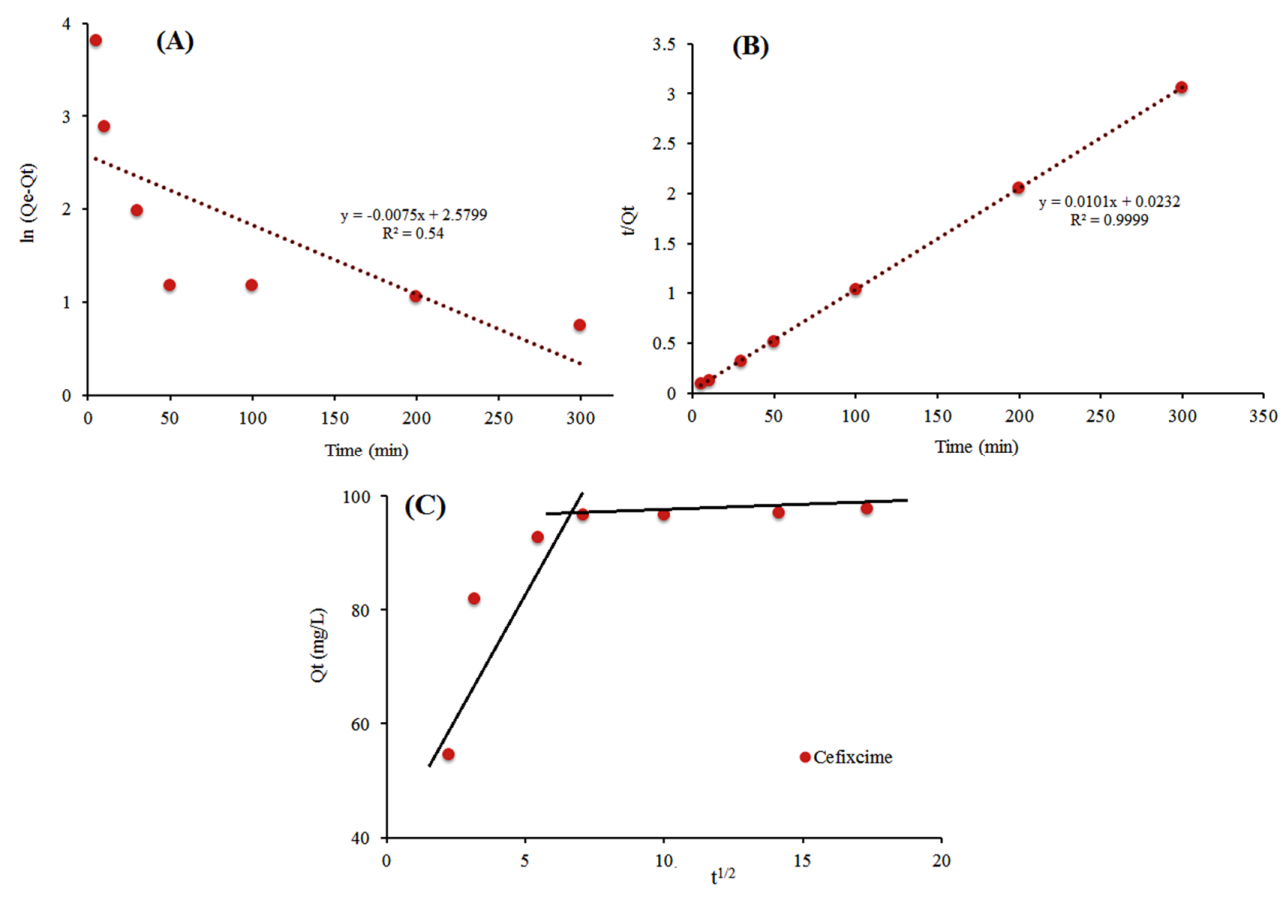

Figure 6. Adsorption kinetic models for (A) pseudo-first-order, (B) pseudo-second-order, and $(\mathbf{C})$ intra-particle diffusion.

Table 1 illustrates the kinetic models and their parameters, which are obtained from linear plots in Figure 6A,B. Regarding the $R^{2}$ values, the pseudo-second-order model $\left(\mathrm{R}^{2}=0.9999\right)$ best fit the experimental data as compared pseudo-first-order $\left(\mathrm{R}^{2}=0.5418\right)$. In addition, the theoretical $q_{e}$ (calculated) based on pseudo-second-order is closer to the $q_{e}$ (experimental) compared to the pseudo-first-order. Thus, a pseudo-second-order model is applicable to evaluation of the cefixime kinetic onto the activated carbon. Previous studies suggested that the pseudo-second-order model probably follows a chemical sorption mechanism for adsorption through electron sharing between analytes and adsorbent [45]. Figure 6C presents a multilinearity sorption process for cefixime: the first sharp step is surface adsorption due to the fast mass transfer from solution to the adsorbent surface [46] and the second step is attributed to the equilibrium sorption on the interior sites of the adsorbent. 
In the second step, the high values of the $C_{i 2}$ also suggest the abundance of adsorbate (analyte) in the boundary layer [47]. This suggests that the cefixime uptake onto PG-AC takes place faster on the surface than on internal sites.

Table 1. The pseudo-first-order, pseudo-second-order and intra-particle diffusion parameters for the adsorption of cefixime (experimental $q_{e}$ was $100.1 \mathrm{mg} \mathrm{g}^{-1}$ ).

\begin{tabular}{ccc}
\hline Model & Parameters & Cefixime \\
\hline Pseudo first order & $q_{e}(\mathrm{mg} / \mathrm{g})$ & 12.84 \\
& $k_{1}(1 / \mathrm{min})$ & 0.0075 \\
Pseudo second order & $R^{2}$ & 0.5418 \\
& $q_{e}(\mathrm{mg} / \mathrm{g})$ & 99.09 \\
& $k_{2}(\mathrm{~g} /(\mathrm{mg} \cdot \mathrm{min}))$ & 0.0001 \\
Intra-particle diffusion & $R^{2}$ & 0.9999 \\
& $K_{i d, 1}$ & 0.7622 \\
& $C_{i 1}$ & 63.405 \\
& $R_{1}{ }^{2}$ & 0.6837 \\
& $K_{i d, 2}$ & 0.0047 \\
& $C_{i 2}$ & 96.356 \\
& $R_{2}{ }^{2}$ & 0.9153 \\
\hline
\end{tabular}

\subsection{Initial Concentration and Adsorption Isotherm}

The equilibrium isotherm was investigated by varying the antibiotic concentration from 10-200 $\mathrm{mg} \mathrm{L}^{-1}$. The batch adsorption process was conducted using $50 \mathrm{mg}$ PG-AC5 at $\mathrm{pH} 3$ for 60 min shaking time at room temperature (Figure 7A). The experimental isotherm equilibrium (A) confirms that the adsorption capacity increased from 5 to $120 \mathrm{mg} \mathrm{g}^{-1}$ by increasing the initial concentration, since a larger amount of analytes was available to load onto the adsorbent active sites. Hence, the adsorption of cefixime onto the PG-AC5 (Figure 7A) was found to be in agreement with Type IV and $\mathrm{V}$ adsorption models set by IUPAC [48]. These types of models are relevant to the multilayer adsorption process.
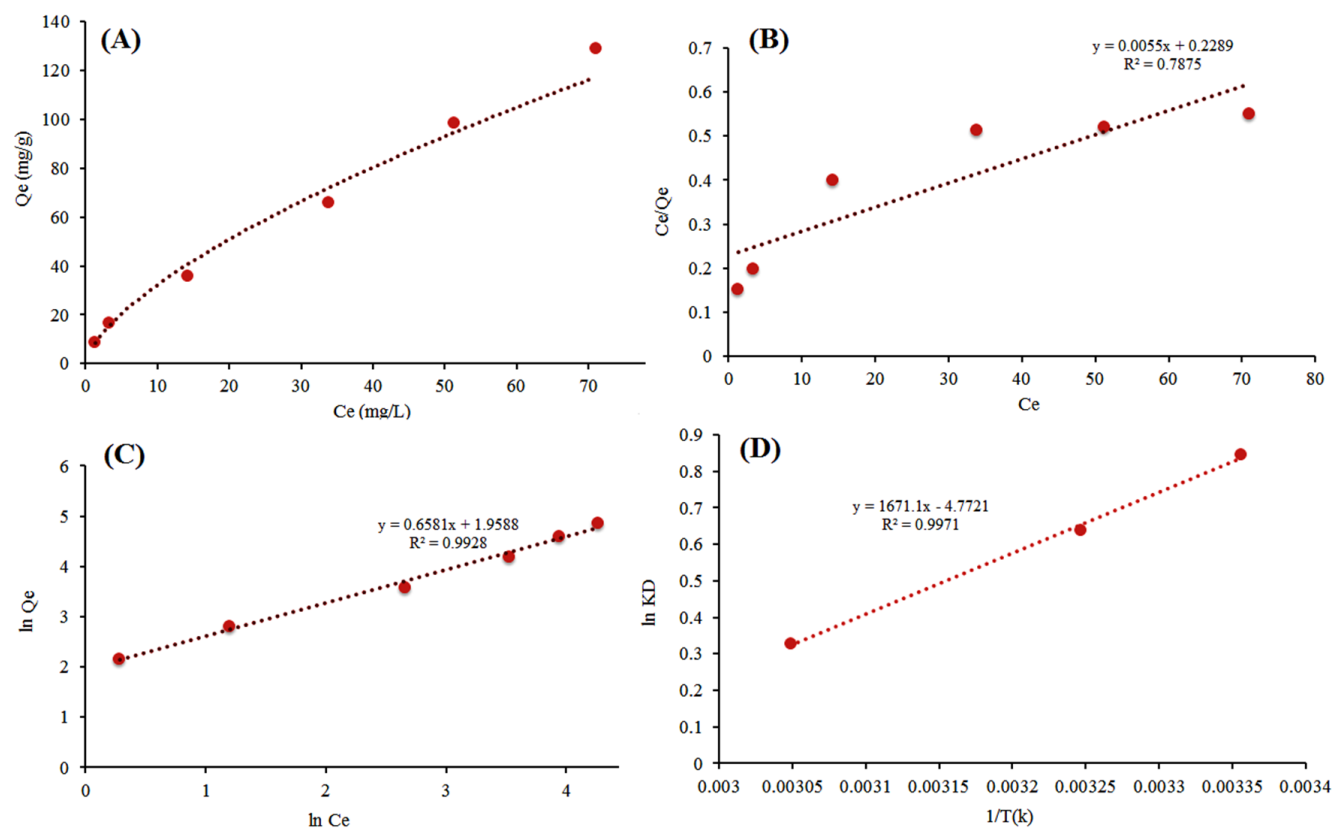

Figure 7. (A) Experimental adsorption isotherm for cefixime adsorption onto PG-AC5, (B) Langmuir isotherm, (C) Freundlich isotherm and (D) thermodynamic model. 
An equilibrium isotherm was performed to evaluate the Langmuir and Freundlich models, seeking to explain the adsorption capacity, the heat of sorption, adsorbent surface heterogeneity, and sorption pattern. The linear form of Langmuir and Freundlich isotherm is expressed under Equations (6) and (7) as follows:

$$
\begin{gathered}
\frac{C_{e}}{q_{e}}=\frac{C_{e}}{q_{m}}+\frac{1}{k_{1 q_{m}}} \\
\ln q_{e}=\ln K_{F}+(1 / n) \ln C_{e}
\end{gathered}
$$

where $C_{e}\left(\mathrm{mg} \mathrm{L}^{-1}\right)$ is the residual concentration of cefixime in solution, $q_{m}\left(\mathrm{mg} \mathrm{g}^{-1}\right)$ is maximum adsorption capacity, $k_{L}$ is Langmuir constant (describing the heat of adsorption), $K_{F}\left[\left(\mathrm{mg} \mathrm{g}^{-1}\right)(\mathrm{L} / \mathrm{mg})^{1 / n}\right]$ and $1 / n$ are the Freundlich constants (intensity of adsorption and heterogeneity factor).

Table 2 and Figure 7B,C illustrate that the adsorption of cefixime onto PG-AC was found to fit well with the Freundlich isotherm, as the Freundlich isotherm provided a higher $R^{2}$ compared to the Langmuir isotherm. Additionally, Freundlich $(n=1.52)$ describes the adsorption of cefixime that occurred on the heterogeneous surface. It suggests a multilayer adsorption pattern for cefixime adsorption onto PG-AC, which was in agreement with the IUPAC protocol.

Table 2. Adsorption isotherm models and parameters for the adsorption of cefixime.

\begin{tabular}{ccc}
\hline Isotherms & Parameters & Cefixime \\
\hline Langmuir & $q_{m}(\mathrm{mg} / \mathrm{g})$ & 181.81 \\
& $k_{L}(\mathrm{~L} / \mathrm{mg})$ & 0.024 \\
& $R^{2}$ & 0.787 \\
Freundlich & $K_{F}\left[(\mathrm{mg} / \mathrm{g})(\mathrm{L} / \mathrm{mg})^{1 / \mathrm{n}}\right]$ & 6.201 \\
& $n$ & 1.52 \\
& $R^{2}$ & 0.992 \\
\hline
\end{tabular}

\subsection{Effect of Temperature and Thermodynamics}

The effect of temperature on the cefixime adsorption process was investigated at three levels: $25^{\circ} \mathrm{C}, 35^{\circ} \mathrm{C}$, and $55^{\circ} \mathrm{C}$ at $\mathrm{pH} 3$, using $50 \mathrm{mg}$ of dosage, 60 min shaking time and concentration of $100 \mathrm{mg} \mathrm{L}^{-1}$ (Figure 7D). A thermodynamic model was performed to evaluate the enthalpy $(\Delta \mathrm{H})$, entropy $(\Delta S)$, and Gibbs free energy $(\Delta \mathrm{G})$ and explain the nature and mechanism of the adsorption of cefixime onto PG-AC. These parameters are described by Van't Hoff equation in Equations (8) and (9).

$$
\begin{aligned}
& \ln K_{D}=-\frac{\Delta H}{R T}+\frac{\Delta S}{R} \\
& -\Delta G=-R T \ln K_{D}
\end{aligned}
$$

where $T(K), R\left(0.0083145 \mathrm{~kJ} \mathrm{~mol}^{-1} \mathrm{~K}^{-1}\right)$ and $K_{D}$ are temperatures, universal gas constant, and the thermodynamic distribution coefficient $\left(\ln K_{D}=q_{e} / C_{e}\right)$, respectively [49].

Table 3 reveals that removal efficiency did not change significantly at different temperatures. In contrast, adsorption capacity decreased from 69.97 to $58.13 \mathrm{mg} \mathrm{g}^{-1}$ when the temperature increased from 25 to $55^{\circ} \mathrm{C}$. The effect of increasing temperature decreased the feasibility of adsorption at high temperatures. The negative values of $\Delta \mathrm{G}, \Delta \mathrm{H}$ and $\Delta \mathrm{S}$ revealed the spontaneous sorption, exothermic nature, and randomness of adsorption for cefixime adsorption onto PG-AC, respectively. The obtained $\Delta G$ values are lower than $-18 \mathrm{~kJ} \mathrm{~mol}^{-1}$, which suggests that the adsorption for cefixime was physical rather than chemical.

\subsection{Regeneration and Recovery}

The adsorption-desorption cycle was repeated fifteen times based on regeneration methodology. The results indicated that the removal efficiency does not decrease significantly up to ten cycles (removal $>87 \%$ ). Thus, the adsorbent can be reused for ten times without a significant loss of removal 
efficiency for water containing $20 \mathrm{mg} \mathrm{L}^{-1}$ cefixime. This result is comparable with other studies in which activated-carbon-based biomass regenerated 4 times $\left(100 \mathrm{mg} \mathrm{L}^{-1}\right)$ [33], 5 times $\left(500 \mathrm{mg} \mathrm{L}^{-1}\right)$ [32], 4 times $\left(200 \mathrm{mg} \mathrm{L}^{-1}\right)$ [50] and 5 times $\left(231 \mathrm{mg} \mathrm{L}^{-1}\right)$ [51].

Table 3. Effect of temperature on removal efficiency and thermodynamic parameters.

\begin{tabular}{rccccc}
\hline Temp ${ }^{\circ} \mathbf{C}$ & Removal $\%$ & $q_{e}(\mathbf{m g} / \mathbf{g})$ & $\Delta \mathrm{G} \mathrm{(kJ/mol)}$ & $\Delta \mathbf{H ~}(\mathbf{k J} / \mathbf{m o l})$ & $\Delta \mathbf{S ~ ( k J / m o l ~ K )}$ \\
\hline 25 & 89 & 69.97 & -2.09 & & \\
35 & 87 & 65.42 & -1.63 & -13.89 & -0.038 \\
55 & 85 & 58.13 & -0.89 & & \\
\hline
\end{tabular}

\subsection{Comparison with Other Adsorbents}

In order to evaluate the sorption efficiency of PG-AC toward cefixime, its ability was compared with other materials such as the adsorption of Portland cement, GO/MNPs-SrTiO 3 , vine wood AC, Biomass-AC, and MGO4 [52-55]. The comparison was conducted in terms of $\mathrm{pH}$, adsorption time, and adsorption capacity of antibiotics on various materials as shown in Table 4. Comparative studies indicate that PG-AC provided a high adsorption capacity $\left(181.81 \mathrm{mg} \mathrm{g}^{-1}\right)$ compared to the other materials, while the lowest was Portland cement $\left(<6 \mathrm{mg} \mathrm{g}^{-1}\right)$ and the highest was biomass-AC $\left(<166 \mathrm{mg} \mathrm{g}^{-1}\right)$. By considering the adsorption time, PG-AC provided fast adsorption compared to Portland cement, vine wood AC and bentonite. Thus, prepared PG-AC is a suitable adsorbent for the efficient and effective adsorption of cefixime antibiotics from aqueous environments.

Table 4. Different ACs used for the removal of antibiotics.

\begin{tabular}{ccccc}
\hline Adsorbent & Antibiotics & Time $\mathbf{( m i n )}$ & $\boldsymbol{q}_{\boldsymbol{e}}(\mathbf{m g} / \mathbf{g})$ & Ref \\
\hline Nano-activated carbon & Cefixime & 60 & 181.81 & This study \\
Portland cement & Cefixime & 180 & 6.99 & {$[52]$} \\
GO/MNPs-SrTiO 3 & Cefotaxime & 30 & 18.21 & {$[43]$} \\
Vine wood AC & Cephalexin & $8 \mathrm{~h}$ & 7.2 & {$[53]$} \\
Biomass-AC & Norfloxacin & 40 & 166.99 & {$[54]$} \\
MGO & Tetracycline & 20 & 39.1 & {$[55]$} \\
\hline
\end{tabular}

\section{Conclusions}

In this study, a new nano-sized PG-AC adsorbent was prepared and its performance for the adsorption of cefixime antibiotic from aqueous media was evaluated. Freundlich models and thermodynamic findings showed that the cefixime uptake follows a multilayer sorption pattern under a physical adsorption process with an endothermic nature. A pseudo-second-order kinetic model provided the best fit for experimental adsorption time and intra-particle diffusion was attributed to equilibrium sorption occurring on the interior sites of the adsorbent. Finally, PG-AC was found to be an efficient and effective adsorbent for the rapid $(60 \mathrm{~min})$ and effective adsorption of cefixime antibiotics with $95 \%$ removed from aqueous environments. Thus, this study proved that pomegranate-based biomass can be used as an alternative adsorbent for remediation of pharmaceutical residuals.

Author Contributions: Investigation, methodology, M.E.B.; writing—original draft preparation, software, Z.P.; writing—review and editing, H.S.; writing—original draft preparation, H.R.N.; writing—review and editing, S.R.; visualization, resources, M.A.K. All authors have read and agreed to the published version of the manuscript.

Funding: This work was supported by Iran's National Elites Foundation with postdoctoral grants funded by the Iranian government (Grant No: 140/13398) and Iran High-Tech Laboratory Network. The authors are grateful to the Faculty of Science and Faculty of Environment (University of Tehran) for their facilitation and financial support.

Conflicts of Interest: The authors declare no conflict of interest. 


\section{References}

1. Ahmed, M.B.; Zhou, J.L.; Ngo, H.H.; Guo, W. Adsorptive removal of antibiotics from water and wastewater: Progress and challenges. Sci. Total Environ. 2015, 532, 112-126. [CrossRef] [PubMed]

2. Bilal, M.; Ashraf, S.S.; Barceló, D.; Iqbal, H.M.N. Biocatalytic degradation/redefining "removal" fate of pharmaceutically active compounds and antibiotics in the aquatic environment. Sci. Total Environ. 2019, 691, 1190-1211. [CrossRef] [PubMed]

3. Mohammadi Nodeh, M.K.; Radfard, M.; Zardari, L.A.; Rashidi Nodeh, H. Enhanced removal of naproxen from wastewater using silica magnetic nanoparticles decorated onto graphene oxide; parametric and equilibrium study. Sep. Sci. Technol. 2018, 15, 2476-2485. [CrossRef]

4. Mailler, R.; Gasperi, J.; Coquet, Y.; Derome, C.; Buleté, A.; Vulliet, E.; Bressy, A.; Varrault, G.; Chebbo, G.; Rocher, V. Removal of emerging micropollutants from wastewater by activated carbon adsorption: Experimental study of different activated carbons and factors influencing the adsorption of micropollutants in wastewater. J. Environ. Chem. Eng. 2016, 4, 1102-1109. [CrossRef]

5. Berendonk, T.U.; Manaia, C.M.; Merlin, C.; Fatta-Kassinos, D.; Cytryn, E.; Walsh, F.; Bürgmann, H.; Sørum, H.; Norström, M.; Pons, M.-N. Tackling antibiotic resistance: The environmental framework. Nat. Rev. Microbiol. 2015, 13, 310-317. [CrossRef]

6. Shokoohia, R.; Leilia, M.; Dargahib, A.; Vazirib, Y.; Khamutianb, R. Common antibiotics in wastewater of Sina and Besat Hospitals, Hamadan, Iran. Arch. Hyg. Sci. 2017, 6, 152-159. [CrossRef]

7. Landers, T.F.; Cohen, B.; Wittum, T.E.; Larson, E.L. A review of antibiotic use in food animals: Perspective, policy, and potential. Public Health Rep. 2012, 127, 4-22. [CrossRef]

8. Fakhri, A.; Adami, S. Adsorption and thermodynamic study of Cephalosporins antibiotics from aqueous solution onto $\mathrm{MgO}$ nanoparticles. J. Taiwan Inst. Chem. Eng. 2014, 45, 1001-1006. [CrossRef]

9. Zavareh, S.; Eghbalazar, T. Efficient and selective removal of cefixime form aqueous solution by a modified bionanocomposite. J. Environ. Chem. Eng. 2017, 5, 3337-3347. [CrossRef]

10. Rouhbakhsh, Z.; Verdian, A.; Rajabzadeh, G. Design of a liquid crystal-based aptasensing platform for ultrasensitive detection of tetracycline. Talanta 2020, 206, 120246. [CrossRef]

11. Kaya, Z.; Kürekçi, F.; Akkuzu, E.; Göral, S.; Kalkan, G. Autoimmune Hemolytic Anemia, Erythrophagocytosis and Liver Dysfunction After Cefixime Use for Urinary Tract Infection in a Child. Indian J. Hematol. Blood Transfus. 2019, 35, 203-204. [CrossRef] [PubMed]

12. Voigt, A.M.; Ciorba, P.; Döhla, M.; Exner, M.; Felder, C.; Lenz-Plet, F.; Sib, E.; Skutlarek, D.; Schmithausen, R.M.; Faerber, H.A. The investigation of antibiotic residues, antibiotic resistance genes and antibiotic-resistant organisms in a drinking water reservoir system in Germany. Int. J. Hyg. Environ. Health 2020, 224, 113449. [CrossRef] [PubMed]

13. Voigt, A.M.; Zacharias, N.; Timm, C.; Wasser, F.; Sib, E.; Skutlarek, D.; Parcina, M.; Schmithausen, R.M.; Schwartz, T.; Hembach, N. Association between antibiotic residues, antibiotic resistant bacteria and antibiotic resistance genes in anthropogenic wastewater-An evaluation of clinical influences. Chemosphere 2020, 241, 125032. [CrossRef]

14. Sharma, S.K.; Kumar, A.; Sharma, G.; Stadler, F.J.; Naushad, M.; Ghfar, A.A.; Ahamad, T. LaTiO2N/Bi2S3 Z-scheme nano heterostructures modified with rGO with high interfacial contact for rapid photocatalytic degradation of tetracycline. J. Mol. Liq. 2020, 311, 113300. [CrossRef]

15. Kumar, A.; Kumar, A.; Sharma, G.; Naushad, M.; Veses, R.C.; Ghfar, A.A.; Stadler, F.J.; Khan, M.R. Solar-driven photodegradation of 17- $\beta$-estradiol and ciprofloxacin from waste water and $\mathrm{CO} 2$ conversion using sustainable coal-char/polymeric-gC 3 N 4/RGO metal-free nano-hybrids. New J. Chem. 2017, 41, 10208-10224. [CrossRef]

16. Sharma, G.; Gupta, V.K.; Agarwal, S.; Bhogal, S.; Naushad, M.; Kumar, A.; Stadler, F.J. Fabrication and characterization of trimetallic nano-photocatalyst for remediation of ampicillin antibiotic. J. Mol. Liq. 2018, 260, 342-350. [CrossRef]

17. Crini, G.; Lichtfouse, E.; Wilson, L.D.; Morin-Crini, N. Conventional and non-conventional adsorbents for wastewater treatment. Environ. Chem. Lett. 2019, 17, 195-213. [CrossRef]

18. Wan Ibrahim, W.A.; Rashidi Nodeh, H.; Sanagi, M.M. Graphene-Based Materials as Solid Phase Extraction Sorbent for Trace Metal Ions, Organic Compounds, and Biological Sample Preparation. Crit. Rev. Anal. Chem. 2016, 46, 267-283. [CrossRef] 
19. Crini, G.; Lichtfouse, E. Advantages and disadvantages of techniques used for wastewater treatment. Environ. Chem. Lett. 2019, 17, 145-155. [CrossRef]

20. Sereshti, H.; Afsharian, E.Z.; Bidhendi, M.E.; Nodeh, H.R.; Kamboh, M.A.; Yilmaz, M. Removal of phosphate and nitrate ions aqueous using strontium magnetic graphene oxide nanocomposite: Isotherms, kinetics, and thermodynamics studies. Environ. Prog. Sustain. Energy 2020, 39, e13332. [CrossRef]

21. Mohammadi Nodeh, M.K.; Soltani, S.; Shahabuddin, S.; Rashidi Nodeh, H.; Sereshti, H. Equilibrium, Kinetic and Thermodynamic Study of Magnetic Polyaniline/Graphene Oxide Based Nanocomposites for Ciprofloxacin Removal from Water. J. Inorg. Organomet. Polym. Mater. 2018, 28, 1226-1234. [CrossRef]

22. Xiang, Y.; Xu, Z.; Wei, Y.; Zhou, Y.; Yang, X.; Yang, Y.; Yang, J.; Zhang, J.; Luo, L.; Zhou, Z. Carbon-based materials as adsorbent for antibiotics removal: Mechanisms and influencing factors. J. Environ. Manag. 2019, 237, 128-138. [CrossRef] [PubMed]

23. Li, W.; Cao, J.; Xiong, W.; Yang, Z.; Sun, S.; Jia, M.; Xu, Z. In-situ growing of metal-organic frameworks on three-dimensional iron network as an efficient adsorbent for antibiotics removal. Chem. Eng. J. 2020, 392, 124844. [CrossRef]

24. Balasubramani, K.; Sivarajasekar, N.; Naushad, M. Effective adsorption of antidiabetic pharmaceutical (metformin) from aqueous medium using graphene oxide nanoparticles: Equilibrium and statistical modelling. J. Mol. Liq. 2020, 301, 112426. [CrossRef]

25. Teixeira, S.; Delerue-Matos, C.; Santos, L. Application of experimental design methodology to optimize antibiotics removal by walnut shell based activated carbon. Sci. Total Environ. 2019, 646, 168-176. [CrossRef]

26. Berrios, M.; Martín, M.Á.; Martín, A. Treatment of pollutants in wastewater: Adsorption of methylene blue onto olive-based activated carbon. J. Ind. Eng. Chem. 2012, 18, 780-784. [CrossRef]

27. Açıkyıldız, M.; Gürses, A.; Karaca, S. Preparation and characterization of activated carbon from plant wastes with chemical activation. Microporous Mesoporous Mater. 2014, 198, 45-49. [CrossRef]

28. Ukanwa, K.S.; Patchigolla, K.; Sakrabani, R.; Anthony, E.; Mandavgane, S. A Review of Chemicals to Produce Activated Carbon from Agricultural Waste Biomass. Sustainability 2019, 11, 6204. [CrossRef]

29. Wei, H.; Wang, H.; Li, A.; Li, H.; Cui, D.; Dong, M.; Lin, J.; Fan, J.; Zhang, J.; Hou, H. Advanced porous hierarchical activated carbon derived from agricultural wastes toward high performance supercapacitors. J. Alloys Compd. 2020, 820, 153111. [CrossRef]

30. Ververi, M.; Goula, A.M. Pomegranate peel and orange juice by-product as new biosorbents of phenolic compounds from olive mill wastewaters. Chem. Eng. Process. Intensif. 2019, 138, 86-96. [CrossRef]

31. Sühnholz, S.; Kopinke, F.-D.; Weiner, B. Hydrothermal treatment for regeneration of activated carbon loaded with organic micropollutants. Sci. Total Environ. 2018, 644, 854-861. [CrossRef] [PubMed]

32. Spessato, L.; Bedin, K.C.; Cazetta, A.L.; Souza, I.P.A.F.; Duarte, V.A.; Crespo, L.H.S.; Silva, M.C.; Pontes, R.M.; Almeida, V.C. KOH-super activated carbon from biomass waste: Insights into the paracetamol adsorption mechanism and thermal regeneration cycles. J. Hazard. Mater. 2019, 371, 499-505. [CrossRef] [PubMed]

33. Akram, M.; Xu, X.; Gao, B.; Yue, Q.; Yanan, S.; Khan, R.; Inam, M.A. Adsorptive removal of phosphate by the bimetallic hydroxide nanocomposites embedded in pomegranate peel. J. Environ. Sci. 2020, 91, 189-198. [CrossRef] [PubMed]

34. Amin, N.K. Removal of direct blue-106 dye from aqueous solution using new activated carbons developed from pomegranate peel: Adsorption equilibrium and kinetics. J. Hazard. Mater. 2009, 165, 52-62. [CrossRef] [PubMed]

35. Ahmad, M.A.; Puad, N.A.A.; Bello, O.S. Kinetic, equilibrium and thermodynamic studies of synthetic dye removal using pomegranate peel activated carbon prepared by microwave-induced $\mathrm{KOH}$ activation. Water Resour. Ind. 2014, 6, 18-35. [CrossRef]

36. Gündüz, F.; Bayrak, B. Biosorption of malachite green from an aqueous solution using pomegranate peel: Equilibrium modelling, kinetic and thermodynamic studies. J. Mol. Liq. 2017, 243, 790-798. [CrossRef]

37. Ali, M.E.M.; Abdelsalam, H.; Ammar, N.S.; Ibrahim, H.S. Response surface methodology for optimization of the adsorption capability of ball-milled pomegranate peel for different pollutants. J. Mol. Liq. 2018, 250, 433-445. [CrossRef]

38. Linares-Solano, A.; Lillo-Rodenas, M.A.; Marco Lozar, J.P.; Kunowsky, M.; Romero Anaya, A.J. NaOH and $\mathrm{KOH}$ for preparing activated carbons used in energy and environmental applications. Int. J. Energy Environ. Econ. 2012, 20, 59-91. 
39. Le Van, K.; Luong Thi Thu, T. Preparation of Pore-Size Controllable Activated Carbon from Rice Husk Using Dual Activating Agent and Its Application in Supercapacitor. J. Chem. 2019, 2019, 1-11. [CrossRef]

40. Martins, A.C.; Pezoti, O.; Cazetta, A.L.; Bedin, K.C.; Yamazaki, D.A.S.; Bandoch, G.F.G.; Asefa, T.; Visentainer, J.V.; Almeida, V.C. Removal of tetracycline by NaOH-activated carbon produced from macadamia nut shells: Kinetic and equilibrium studies. Chem. Eng. J. 2015, 260, 291-299. [CrossRef]

41. Ji, Y.; Li, T.; Zhu, L.; Wang, X.; Lin, Q. Preparation of activated carbons by microwave heating KOH activation. Appl. Surf. Sci. 2007, 254, 506-512. [CrossRef]

42. Gao, Y.; Yue, Q.; Gao, B.; Sun, Y.; Wang, W.; Li, Q.; Wang, Y. Comparisons of porous, surface chemistry and adsorption properties of carbon derived from Enteromorpha prolifera activated by $\mathrm{H} 4 \mathrm{P} 2 \mathrm{O} 7$ and $\mathrm{KOH}$. Chem. Eng. J. 2013, 232, 582-590. [CrossRef]

43. Rashidi Nodeh, H.; Sereshti, H. Synthesis of magnetic graphene oxide doped with strontium titanium trioxide nanoparticles as a nanocomposite for the removal of antibiotics from aqueous media. RSC Adv. 2016, 6, 89953-89965. [CrossRef]

44. Shivashankar, M.; Mandal, B.K. Design and Evaluation of Chitosan-Based Novel pH-Sensitive Drug Carrier for Sustained Release of Cefixime. Trop. J. Pharm. Res. 2013, 12, 155-161.

45. Güzel, F.; Sayğılı, H.; Sayğı1ı, G.A.; Koyuncu, F.; Yılmaz, C. Optimal oxidation with nitric acid of biochar derived from pyrolysis of weeds and its application in removal of hazardous dye methylene blue from aqueous solution. J. Clean. Prod. 2017, 144, 260-265. [CrossRef]

46. Ali, R.M.; Hamad, H.A.; Hussein, M.M.; Malash, G.F. Potential of using green adsorbent of heavy metal removal from aqueous solutions: Adsorption kinetics, isotherm, thermodynamic, mechanism and economic analysis. Ecol. Eng. 2016, 91, 317-332. [CrossRef]

47. Ghodbane, I.; Hamdaoui, O. Removal of mercury (II) from aqueous media using eucalyptus bark: Kinetic and equilibrium studies. J. Hazard. Mater. 2008, 160, 301-309. [CrossRef]

48. Sing, K.S.W. Reporting physisorption data for gas/solid systems with special reference to the determination of surface area and porosity (IUPAC recommendations 1984). Pure Appl. Chem. 1985, 57, 603-619. [CrossRef]

49. Kalantary, R.R.; Azari, A.; Esrafili, A.; Yaghmaeian, K.; Moradi, M.; Sharafi, K. The survey of Malathion removal using magnetic graphene oxide nanocomposite as a novel adsorbent: Thermodynamics, isotherms, and kinetic study. Desalin. Water Treat. 2016, 57, 1-14. [CrossRef]

50. Bhomick, P.C.; Supong, A.; Baruah, M.; Pongener, C.; Sinha, D. Pine Cone biomass as an efficient precursor for the synthesis of activated biocarbon for adsorption of anionic dye from aqueous solution: Isotherm, kinetic, thermodynamic and regeneration studies. Sustain. Chem. Pharm. 2018, 10, 41-49. [CrossRef]

51. Ge, X.; Wu, Z.; Cravotto, G.; Manzoli, M.; Cintas, P.; Wu, Z. Cork wastewater purification in a cooperative flocculation/adsorption process with microwave-regenerated activated carbon. J. Hazard. Mater. 2018, 360, 412-419. [CrossRef] [PubMed]

52. Rasoulifard, M.H.; Khanmohammadi, S.; Heidari, A. Adsorption of cefixime from aqueous solutions using modified hardened paste of Portland cement by perlite; optimization by Taguchi method. Water Sci. Technol. 2016, 74, 1069-1078. [CrossRef] [PubMed]

53. Pouretedal, H.R.; Sadegh, N. Effective removal of Amoxicillin, Cephalexin, Tetracycline and Penicillin G from aqueous solutions using activated carbon nanoparticles prepared from vine wood. J. Water Process Eng. 2014, 1, 64-73. [CrossRef]

54. Ahmed, M.J.; Theydan, S.K. Fluoroquinolones antibiotics adsorption onto microporous activated carbon from lignocellulosic biomass by microwave pyrolysis. J. Taiwan Inst. Chem. Eng. 2014, 45, 219-226. [CrossRef]

55. Lin, Y.; Xu, S.; Li, J. Fast and highly efficient tetracyclines removal from environmental waters by graphene oxide functionalized magnetic particles. Chem. Eng. J. 2013, 225, 679-685. [CrossRef]

(C) 2020 by the authors. Licensee MDPI, Basel, Switzerland. This article is an open access article distributed under the terms and conditions of the Creative Commons Attribution (CC BY) license (http://creativecommons.org/licenses/by/4.0/). 